\title{
Analyst
}

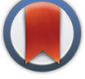

CrossMark \&lick for updates

Cite this: Analyst, 2016, 141, 3993

Received 29th March 2016, Accepted 11th May 2016

DOI: 10.1039/c6an00735j

www.rsc.org/analyst

\section{Signal enhancement in ligand-receptor interactions using dynamic polymers at quartz crystal microbalance sensors $\uparrow$}

\author{
Gunnar Dunér, ${ }^{a, b}$ Henrik Anderson, ${ }^{b, c}$ Zhichao Pei, $^{b}$ Björn Ingemarsson, ${ }^{b}$ \\ Teodor Aastrup ${ }^{\mathrm{b}}$ and Olof Ramström ${ }^{\star a}$
}

The signal enhancement properties of QCM sensors based on dynamic, biotinylated poly(acrylic acid) brushes has been studied in interaction studies with an anti-biotin $F_{a b}$ fragment. The poly (acrylic acid) sensors showed a dramatic increase in signal response with more than ten times higher signal than the carboxyl-terminated self-assembled monolayer surface.

Quartz Crystal Microbalance (QCM) sensors have been widely employed in real-time, label-free biomolecular interaction studies. $^{1-5}$ There is a broad variety of assays; for example immunoassays of various formats, assays targeting viruses and bacteria, detection of cell adhesion, sensing of lipid interactions to membranes, and assays of carbohydrate-protein interactions. ${ }^{6-22}$ In these studies, the receptor of the system is often immobilized on self-assembled monolayers (SAMs) of carboxyl-terminated alkane thiols, bound to the gold electrode of the QCM sensor. This generally results in adequate signal levels, but in cases where the signal is low, amplification techniques can be applied to produce an enhanced signal. ${ }^{23,24}$ In QCM affinity studies, a relatively new concept for signal enhancement is for example to make use of nanoparticles as signal amplifiers, due to their large masses. ${ }^{25-31}$ Another strategy is to use enzyme-catalyzed reactions to produce precipitates that attach to the QCM electrode. ${ }^{32,33}$ However, sensors that make use of SAMs are conceptually restricted to the active surface area of the sensor, whereas sensors exploiting an additional height dimension are, hypothetically, capable of binding more receptors. A three-dimensional surface can in principle bind several monolayers of protein provided the matrix is fully permeable. One methodology that is in line with this approach is to make use of carboxymethyl-modified dextran, where the carboxyl groups used for receptor binding

${ }^{a}$ KTH - Royal Institute of Technology, Department of Chemistry, Teknikringen 30, S-10044 Stockholm, Sweden.E-mail: ramstrom@kth.se

${ }^{b}$ Attana AB, Björnnäsvägen 21, S-11419 Stockholm, Sweden

${ }^{c}$ Uppsala University, Ångström Laboratory, Solid State Electronics, P.O. Box 534, S-75121 Uppsala, Sweden

$\dagger$ Electronic supplementary information (ESI) available: Synthesis, sensor fabrication, QCM analyses. See DOI: 10.1039/c6an00735j are not restricted to a flat surface, but to a hydrogel that can protrude up to $100 \mathrm{~nm}$ from the surface into the buffer solution. ${ }^{34,35}$ The latter surface has for a long time been successfully employed using for example the surface plasmon resonance-technology. ${ }^{36}$ For QCM sensors, the use of polymerbased sensor surfaces for signal amplification in biomolecular interaction analysis has not been extensively studied. Biopolymeric dextran layers on QCM surfaces, although not comprehensively explored, have for example shown low signal enhancement properties. ${ }^{37}$ Previously studied acrylamide/acrylate-brushes on QCM substrates, however, have exhibited very large dynamic signals in response to $\mathrm{pH}$ changes. ${ }^{38,39}$ This methodology, where polymer brushes based on the photoiniferter technique were synthesized in situ at the sensor surface, has the potential to yield highly functionalized sensor layers. In the present study, we have explored the applicability of this technique to create high density ligand surfaces based on poly (acrylic acid) (pAAc) brushes. These polymer chains were subsequently functionalized with a biotin derivative, and the interaction with an anti-biotin $\mathrm{F}_{\mathrm{ab}}$-fragment was evaluated. For comparison, the same interaction system was tested using commercial sensor surfaces with carboxyl-terminated selfassembled monolayers.

The fabrication of the polymer-based QCM sensors is outlined in Fig. 1. Gold-plated $10 \mathrm{MHz}$ QCM crystals were first spincoated with the photoreactive macroinitiator copolymer poly(vinylbenzyl chloride-co-vinylbenzyl diethylcarbamodithioate) $\left(\mathrm{PVBD}_{501}\right)$, containing $2 \mathrm{~mol} \%$ iniferter groups. Polymerization of acrylic acid under UV irradiation subsequently yielded poly(acrylic acid) brushes, resulting in sensor surfaces of three-dimensional character.

Functionalization with (+)-biotinyl 3,6,9-trioxaundecanediamine was subsequently carried out in situ using the QCM flow-through instrumentation where identical protocols were used for both the pAAc-based sensors and the carboxyl-terminated SAM surfaces. Thus, following equilibration of the sensors in running buffer, a mixture of EDC and sulfo-NHS was injected to activate the surfaces. Subsequent injection of the biotin derivative resulted in derivatization of the carboxyl 


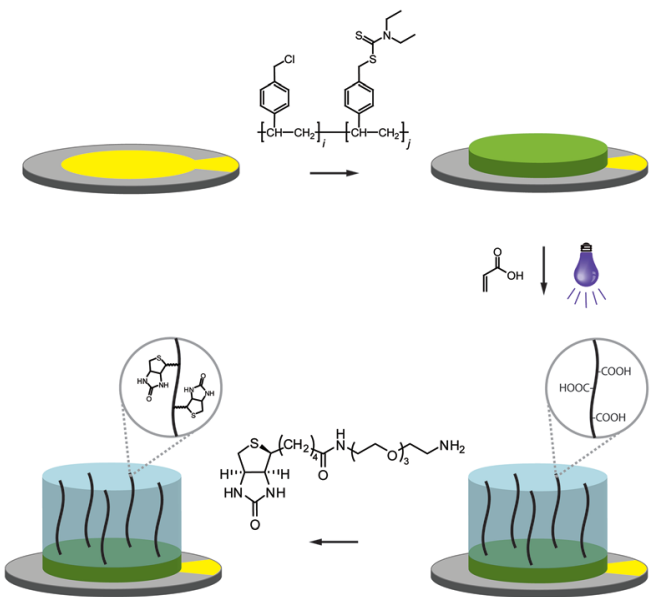

Fig. 1 Fabrication of biotin-functionalized pAAc sensor. Gold-plated QCM crystals were first coated with the photoreactive copolymer $\mathrm{PVBD}_{501}$, which was subsequently subjected to poly(acrylic acid) brush formation under UV irradiation. Final coupling of (+)-biotinyl 3,6,9-trioxaundecanediamine to the carboxylic acid groups yielded functionalized QCM sensor surfaces of three-dimensional character.

groups, and unreacted NHS-esters were deactivated by injection of excess ethanolamine. The process was monitored in real time as displayed in Fig. 2. The frequency responses proved slightly different for the pAAc sensors and the carboxylterminated SAM sensors. For the carboxyl-terminated SAM sensors, the frequency decreased during both injection of EDC/sulfo-NHS and deactivation with ethanolamine, but increased during injection of (+)-biotinyl 3,6,9-trioxaundecanediamine. As expected, a low residual frequency change after the derivatization step was observed given the low molecular weight of the biotin derivative. In the case of the pAAc surface on the other hand, the frequency immediately increased upon injection of EDC/sulfo-NHS, followed by a subsequent, close to linear, drop in frequency during the remaining injection time. Following replacement of the injected sample by running buffer, the frequency stabilized at a higher frequency level. The subsequent injection of the (+)-biotinyl 3,6,9-trioxaundecane-

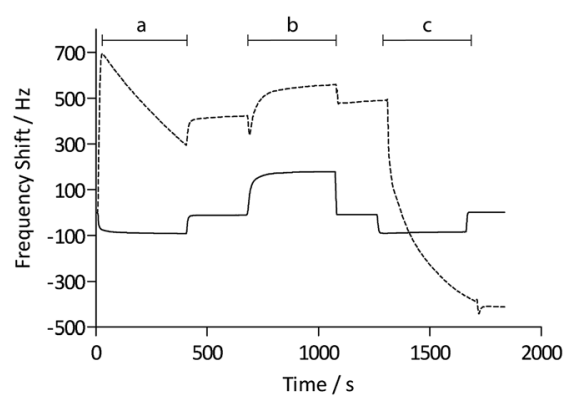

Fig. 2 Frequency responses of the surface derivatization process at the pAAc surface (---), and the carboxyl-terminated SAM surface (-), respectively. Injections for activation by EDC/sulfo-NHS (a); functionalization with (+)-biotinyl 3,6,9-trioxaundecanediamine (b); and deactivation by ethanolamine (c), are indicated in the graph. diamine then resulted in a frequency increase, similar to the carboxyl-terminated SAM surface, which stabilized at a higher frequency level. Upon the final injection of ethanolamine, however, the frequency dropped throughout the injection and stabilized at a level lower than prior to injection. This behavior is indicative of a dynamic effect of the polymer brushes, where the composition and charge of the material result in frequency shifts. ${ }^{39}$ Clearly, dynamic responses are particularly associated with the activation- and deactivation steps, since the frequency changes are unrelated to direct mass changes of the polymer brushes. The shifts are thus in part likely to be attributed to the residual charge and extension of the polymer brushes, and in part changes in viscoelasticity of the pAAc layer. In addition, transient bulk frequency responses arise from injection of solutions of different $\mathrm{pH}$, as further shown in Fig. $\mathrm{S} 1, \uparrow$ and show the expected behavior of frequency increase upon injection of solutions of lower $\mathrm{pH}$ than the neutral running buffer, corresponding to loss of sensed water.

To assess the functionality of the pAAc surface in terms of biological activity and ligand availability, the interaction between the sensor surfaces and anti-biotin $\mathrm{F}_{\mathrm{ab}}$ fragments was studied. The $\mathrm{F}_{\mathrm{ab}}$ fragments were dissolved in running buffer $\left(25 \mu \mathrm{g} \mathrm{mL}^{-1}\right)$ and injected over the sensor surface at a flow rate of $25 \mu \mathrm{L} \mathrm{min}{ }^{-1}$ for $400 \mathrm{~s}$. As can be seen in Fig. 3, the binding of anti-biotin $\mathrm{F}_{\mathrm{ab}}$ fragments to the sensor surfaces resulted in a continuous decrease in resonance frequency during the full association phase, indicating that equilibrium was not completely reached during this period. To ensure that the observed frequency response was due to the specific interaction between the biotin-functionalized sensors and the anti-biotin $\mathrm{F}_{\mathrm{ab}}$ fragments, two different controls were performed (Fig. 3). First, a pAAc surface was prepared by the EDC/sulfo-NHS functionalization method used for the biotin-presenting sensors, but omitting the introduction of the biotin derivative. The resulting activated-deactivated sensor was subsequently exposed to anti-biotin $\mathrm{F}_{\mathrm{ab}}$ fragments, but did not display any significant residual binding. This indicates that the anti-biotin $\mathrm{F}_{\mathrm{ab}}$ fragment does not bind non-specifically to the matrix after deactivation. Secondly, a control protein, lysozyme, was used as

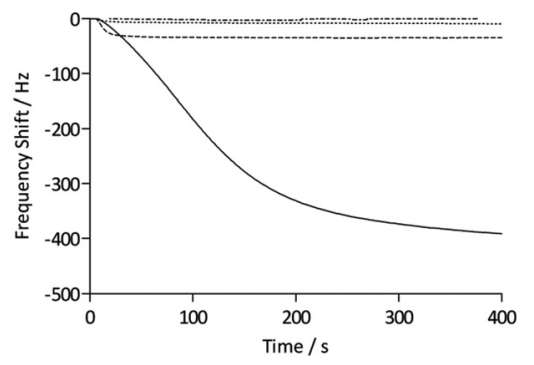

Fig. 3 Frequency responses of protein binding to QCM sensors. Antibiotin $\mathrm{F}_{\mathrm{ab}}$ binding to biotin-derivatized pAAc surface (-); anti-biotin $\mathrm{F}_{\mathrm{ab}}$ binding to biotin-derivatized carboxyl-terminated SAM surface (---); anti-biotin $F_{a b}$ binding to deactivated pAAc surface (-•-); lysozyme binding to biotin-derivatized pAAc surface (...). Sample concentrations:

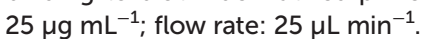


negative control because of its small size $\left(M_{\mathrm{w}}=14.7 \mathrm{kDa}\right)$ and high isoelectric point $(\mathrm{pI}=11.4)$, resulting in a net positive charge at the conditions used ( $\mathrm{pH}$ 7.4). For comparison, the anti-biotin $\mathrm{F}_{\mathrm{ab}}$ fragment showed strong isoelectric focusing bands at $\mathrm{pH} \sim 8$ (Phast System, Pharmacia, data not shown). Exposure of lysozyme to the biotinylated pAAc sensors resulted in a minimal frequency response, showing that non-specific binding to residual negatively charged moieties in the matrix due to electrostatic attraction is limited. This confirms that the observed frequency responses of the anti-biotin $\mathrm{F}_{\mathrm{ab}}$ fragments on the biotinylated pAAc sensors are the result of biospecific interactions, and that the general level of non-specific binding to the developed pAAc sensors is low. The ability to regenerate the sensor surfaces, an important property for biosensors, could be demonstrated by injecting glycine $(10 \mathrm{mM}, \mathrm{pH} 1.5)$ for $60 \mathrm{~s}$ over the sensor, which removed all bound anti-biotin $\mathrm{F}_{\mathrm{ab}}$ and restored the frequency to the original base line (Fig. 4). Successful regeneration was also confirmed by performing repetitive binding cycles that resulted in similar binding levels of anti-biotin $\mathrm{F}_{\mathrm{ab}}$.

To evaluate the signal amplification obtained using the three-dimensional polymer structures of the QCM sensors, the carboxyl-terminated SAM sensors functionalized with the biotin derivative were assessed in the same way as the pAAc sensors (Fig. 3). The maximum response of the anti-biotin $\mathrm{F}_{\mathrm{ab}}$ fragments on the SAM sensors was $35 \mathrm{~Hz}$, to be compared to the $440 \pm 50 \mathrm{~Hz}$ response recorded for the pAAc sensors. Evidently, the use of pAAc brushes results in a significant signal increase with an 11 times higher response than for the carboxyl-terminated SAM surface. The three-dimensional nature of the matrix, in combination with potential dynamic effects, thus resulted in strong signal enhancement.

The QCM analyses also revealed additional characteristics of the surfaces. The initial rate of binding appeared lower for the pAAc sensors compared to the carboxyl-terminated SAM sensors, as seen in Fig. 3. This behavior is most likely due to mass-transport phenomena in the polymer-based matrices, where, for example, the diffusion rate for a particle is expected to be lower than for a free moving particle that adsorbs to a

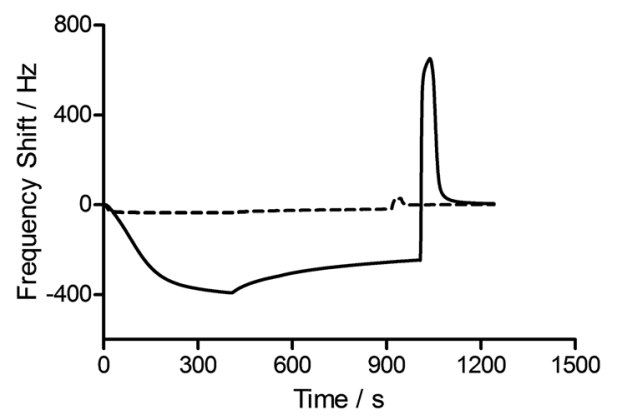

Fig. 4 Frequency responses of protein binding and sensor surface regeneration. Anti-biotin $F_{a b}$ binding to biotin-derivatized pAAc surface $(-)$; anti-biotin $\mathrm{F}_{\mathrm{ab}}$ binding to biotin-derivatized carboxyl-terminated SAM surface (---). Sample concentrations: $25 \mu \mathrm{g} \mathrm{mL}^{-1}$; flow rate: $25 \mu \mathrm{L}$ $\mathrm{min}^{-1}$. Surfaces were regenerated with glycine $(10 \mathrm{mM}, \mathrm{pH} 1.5)$. surface. The binding curves for the pAAc matrices were also slightly sigmoidal in shape. This could stem from the fact that the sensing capability, as given by the characteristic decay length, is lowest at the top domains of the pAAc matrix. As shown by Kanazawa and Gordon, the amplitude of lateral displacement decays exponentially for a quartz crystal with one side facing a liquid medium. ${ }^{40}$ This means that the same number of molecules gives rise to a higher response if they are sensed closer to the surface of the quartz crystal, and that changes in liquid viscosity and density may affect the sensing performance of the quartz crystal. Since the sensitivity is highest at the shortest distance to the surface of the QCM electrode, gradual response shifts are expected over the matrix. The sigmoidal characteristic of the binding can thus be interpreted such that the initial population of protein molecules binds at the top domain, giving rise to a smaller response, whereas subsequent penetration of the matrix gives rise to a higher response.

Responses of QCM sensors with dynamic polymer surfaces are complex and their interpretations are non-trivial, as demonstrated by the functionalization procedure on the pAAc sensors. For instance, sensor responses due to changes in polymer viscosity and changes in coupling of water to the polymer may occur, in addition to the commonly experienced aspects of bulk responses and coupling of water to protein adlayers. ${ }^{41}$ In an effort to gain better understanding of the viscoelastic aspects of the protein binding to the sensor surfaces, the motional resistance was measured together with the frequency for the binding of the anti-biotin $\mathrm{F}_{\mathrm{ab}}$ fragments. As described by Lucklum et al., the change in resistance divided by the change in frequency, $\Delta R / \Delta F$, can be used as measure of the viscoelastic contribution to the observed frequency change. ${ }^{42}$ The resulting $\Delta R / \Delta F$ ratio for anti-biotin $\mathrm{F}_{\mathrm{ab}}$ binding to the carboxyl-terminated SAM surface was $3.7 \mathrm{~m} \Omega \mathrm{Hz}^{-1}$, whereas a value of $10 \mathrm{~m} \Omega \mathrm{Hz}^{-1}$ was recorded for the pAAc sensors. Thus, the pAAc sensors show approximately three times higher viscoelastic contribution to the frequency response than the carboxyl-terminated SAM sensors, which confirms an expected behavior where proteins bound to the pAAc polymer are less rigidly attached to the surface than those bound to the SAM sensor surface.

\section{Conclusions}

This study has shown that highly functional polymer sensor surfaces can be synthesized on QCM substrates by means of a photoiniferter polymerization technique. The sensors were functionalized with a biotin derivative in situ, and shown to provide specific interaction data for a model system with antibiotin $\mathrm{F}_{\mathrm{ab}}$ fragments. The sensors could furthermore be efficiently regenerated, and residual non-specific binding was found to be low. In comparison to carboxyl-terminated SAM sensors, the pAAc sensors displayed a dramatic increase in signal response, where eleven times higher frequency shifts could be recorded. Thus, it is clear that polymer-based sensors can be successfully applied to amplify the response signals of 
QCM sensors, a feature potentially attractive for studies of interactions between receptors and low molecular weight compounds. Furthermore, these materials are in principle amenable to ligand-induced dynamic responses, suitable for applications where controlled signal enhancements are desired.

\section{Acknowledgements}

The authors thank the Swedish Research Council for financial support.

\section{References}

1 K. S. McKeating, A. Aubé and J.-F. Masson, Analyst, 2016, 141, 429-449.

2 C. I. Cheng, Y.-P. Chang and Y.-H. Chu, Chem. Soc. Rev., 2012, 41, 1947-1971.

3 R. E. Speight and M. A. Cooper, J. Mol. Recognit., 2012, 25, 451-473.

4 B. Becker and M. A. Cooper, J. Mol. Recognit., 2011, 24, 754787.

5 B. Godber, M. Frogley, M. Rehak, A. Sleptsov, K. S. J. Thompson, Y. Uludag and M. A. Cooper, Biosens. Bioelectron., 2007, 22, 2382-2386.

6 H.-Y. Li, T.-H. Hsu, C.-Y. Chen, M.-C. Tseng and Y.-H. Chu, Analyst, 2015, 140, 6245-6249.

7 A. Palaniappan, J. A. Cheema, D. Rajwar, G. Ammanath, L. Xiaohu, L. Seng Koon, W. Yi, U. H. Yildiz and B. Liedberg, Analyst, 2015, 140, 7912-7917.

8 S. Uppalapati, N. Kong, O. Norberg, O. Ramström and M. Yan, Appl. Surf. Sci., 2015, 343, 166-171.

9 X. Zhu, Z. Wang, A. Zhao, N. Huang, H. Chen, S. Zhou and X. Xie, Colloids Surf., B, 2014, 116, 459-464.

10 D. Tang, B. Zhang, J. Tang, L. Hou and G. Chen, Anal. Chem., 2013, 85, 6958-6966.

11 A. K. Trilling, J. Beekwilder and H. Zuilhof, Analyst, 2013, 138, 1619-1627.

12 C. Crosson and C. Rossi, Biosens. Bioelectron., 2013, 42, 453-459.

13 P. I. Reyes, Z. Duan, Y. Lu, D. Khavulya and N. Boustany, Biosens. Bioelectron., 2013, 41, 84-89.

14 Z. Pei, J. Saint-Guirons, C. Käck, B. Ingemarsson and T. Aastrup, Biosens. Bioelectron., 2012, 35, 200-205.

15 O. Norberg, I. H. Lee, T. Aastrup, M. Yan and O. Ramström, Biosens. Bioelectron., 2012, 34, 51-56.

16 V. Agmo Hernandez, K. Reijmar and K. Edwards, Biophys. J., 2012, 102, 492a.

17 O. Norberg, L. Deng, T. Aastrup, M. Yan, O. Ramström and O. Ramström, Anal. Chem., 2011, 83, 1000-1007.

18 Z. Pei, H. Anderson, A. Myrskog, G. Dunér, B. Ingemarsson and T. Aastrup, Anal. Biochem., 2010, 398, 161-168.
19 O. Norberg, L. Deng, M. Yan and O. Ramström, Bioconjugate Chem., 2009, 20, 2364-2370.

20 Z. Pei, H. Anderson, T. Aastrup and O. Ramström, Biosens. Bioelectron., 2005, 21, 60-66.

21 Z. Pei, T. Aastrup, H. Anderson and O. Ramström, Bioorg. Med. Chem. Lett., 2005, 15, 2707-2710.

22 X. Su, F. T. Chew and S. F. Y. Li, Anal. Sci., 2000, 16, 107114.

23 H. Aizawa, S. Kurosawa, M. Tozuka, J.-W. Park, K. Kobayashi and H. Tanaka, Biosens. Bioelectron., 2003, 18, 765-771.

24 H. Aizawa, S. Kurosawa, M. Tozuka, J.-W. Park and K. Kobayashi, Sens. Actuators, B, 2004, 101, 150-154.

25 P. He, L. Liu, W. Qiao and S. Zhang, Chem. Commun., 2014, 50, 1481-1484.

26 E. Mahon, Z. Mouline, M. Silion, A. Gilles, M. Pinteala and M. Barboiu, Chem. Commun., 2013, 3004-3006.

27 P. Ding, R. Liu, S. Liu, X. Mao, R. Hu and G. Li, Sens. Actuators, $B, 2013, \mathbf{1 8 8}, 1277-1283$.

28 Y. Uludag and I. E. Tothill, Anal. Chem., 2012, 84, 58985904.

29 M. J. Kim, Y. K. Choi, S. Kim, D. Kim, K. Han, S. B. Ko and J. Park, Org. Lett., 2008, 10, 1295-1298.

30 Y.-K. Lyu, K.-R. Lim, B. Y. Lee, K. S. Kim and W.-Y. Lee, Chem. Commun., 2008, 4771-4773.

31 H. Xia, F. Wang, Q. Huang, J. Huang, M. Chen, J. Wang, C. Yao, Q. Chen, G. Cai and W. Fu, Sensors, 2008, 8, 64536470.

32 Y. Ding, H. Wang, G. Shen and R. Yu, Anal. Bioanal. Chem., 2005, 382, 1491-1499.

33 R. C. Ebersole and M. D. Ward, J. Am. Chem. Soc., 1988, 110, 8623-8628.

34 B. Johnsson, S. Löfås and G. Lindquist, Anal. Biochem., 1991, 198, 268-277.

35 S. Löfås and B. Johnsson, J. Chem. Soc., Chem. Commun., 1990, 1526.

36 R. L. Rich and D. G. Myszka, J. Mol. Recognit., 2008, 21, 355-400.

37 S. Storri, T. Santoni, M. Minunni and M. Mascini, Biosens. Bioelectron., 1998, 13, 347-357.

38 G. Dunér, E. Thormann, O. Ramström and A. Dédinaitė, J. Dispersion Sci. Technol., 2010, 31, 1285-1287.

39 G. Dunér, H. Anderson, A. Myrskog, M. Hedlund, T. Aastrup and O. Ramström, Langmuir, 2008, 24, 75597564.

40 K. K. Kanazawa and J. G. Gordon, Anal. Chim. Acta, 1985, 175, 99-105.

41 F. Höök and B. Kasemo, in Piezoelectric Sensors, ed. C. Steinem and A. Janshoff, Springer, Berlin Heidelberg, 2007, pp. 425-447.

42 R. Lucklum, C. Behling and P. Hauptmann, Anal. Chem., 1999, 71, 2488-2496. 